\title{
Anatomy of the Aqueous Outflow Drainage Pathways
}

\author{
Kay Lam and Mitchell Lawlor
}

\section{$2.1 \quad$ Introduction}

Minimally invasive glaucoma surgery (MIGS) encompasses a group of procedures aiming to lower intraocular pressure (IOP) with reduced surgical times, more rapid postoperative recovery and a better safety profile compared with traditional filtration surgery. Increasing aqueous humour $(\mathrm{AH})$ outflow may be achieved either through facilitating the existing pathways of Schlemm's canal and the suprachoroidal space or to bypass the normal angle anatomy to create a full thickness fistula into the subconjunctival space. Because of the importance of the anterior chamber angle in the pathogenesis of glaucomatous damage, an understanding of angle anatomy and aqueous outflow structures is critical to surgical planning and device selection for particular glaucoma subtypes. This chapter reviews the clinically relevant anatomy and functionality of the outflow apparatus in the human eye.

\subsection{Aqueous Humour Outflow}

Intraocular pressure, the main risk factor for glaucoma, is determined by the production, circulation and drainage of $\mathrm{AH}$. The major drainage pathways are the trabecular outflow pathway (conventional outflow) and uveoscleral outflow pathway (unconventional outflow). Aqueous draining through the trabecular outflow system will traverse the trabecular meshwork, through the juxtacanalicular connective tissue, into Schlemm's canal and the collecting channels, and finally into the aqueous veins which then drain into the episcleral venous system. AH draining through the

K. Lam

University of Toronto, Toronto, Ontario, Canada

M. Lawlor ( $\square)$

University of Sydney, Sydney, NSW, Australia

e-mail: mitchell.lawlor@ sydney.edu.au 
uveoscleral route passes through the ciliary muscle bundles into the suprachoroidal space and then through the sclera into the orbital vessels [1].

The relative contribution of each of these outflow pathways is difficult to determine as it changes depending on the species studied and the method of measurement used. Nonetheless, it is clear that in humans, trabecular meshwork is the major pathway for aqueous outflow accounting for approximately 70-95\% of drainage [2, 3]. Uveoscleral outflow in healthy subjects had traditionally been thought to represent a much smaller proportion of $\mathrm{AH}$ drainage in healthy humans than primates, though formal aqueous flow studies have reported a value of about 35\% in young adults and 3\% for individuals over 60 years of age [1, 4]. Aside from the relative contribution of outflow of the two pathways, there are a number of other important differences. Firstly, outflow from the anterior chamber across the trabecular meshwork into Schlemm's canal is pressure dependent, whereas uveoscleral outflow is pressure independent in the physiological range $[5,6]$. Secondly, with advancing age, both the trabecular meshwork and uveoscleral outflow facility gradually decline, although there is a relatively greater decline in the uveoscleral contribution to AH drainage overall [2]. To compensate for this, production of $\mathrm{AH}$ also decreases with age and therefore IOP is relatively unchanged in the healthy aging human eye [2]. In contrast, eyes with primary open-angle glaucoma have higher outflow resistance in the trabecular outflow pathway than in agematched normal control eyes, while secretion of $\mathrm{AH}$ is not changed $[7,8]$.

\subsection{Trabecular Meshwork}

The main ocular structures related to the trabecular outflow pathways are located around the scleral sulcus, a circular groove of the inner sclera, adjacent to the corneoscleral limbus [9]. The sulcus begins at the peripheral termination of Descemet's membrane and extends to the scleral spur, a ridge of inner scleral fibres that run parallel to the limbus, and project inward. This important landmark divides the conventional from the unconventional or uveoscleral outflow. It is best viewed by gonioscopy as no imaging device yet consistently identifies the scleral spur. The scleral spur may also play a role in preventing the ciliary muscle from causing Schlemm's canal to collapse [10]. Schlemm's canal, a circular tube, lies in the outer aspect of the scleral sulcus, while the trabecular meshwork lies at its inner aspect. The trabecular meshwork comprises connective tissue beams or lamellae that are interconnected in several layers to form a porous structure (Fig. 2.1). Each trabecular beam is covered by flat epithelial-like trabecular meshwork cells thought to provide self-cleaning phagocytic activity to maintain the porous structure. Anteriorly, the trabecular beams are attached to the peripheral cornea near the end of Descemet's membrane (Schwalbe's line) and extend posteriorly to ciliary body stroma and scleral spur. The spaces of the trabecular meshwork range in size from 20 to $75 \mu \mathrm{m}$ and progressively decrease in size posteriorly. The trabecular band covers the internal aspect of Schlemm's canal and is relatively featureless in the unpigmented eye. However, when the meshwork is pigmented, the pigment is concentrated over the canal of Schlemm. Thus, the anterior nonpigmented portion of the trabecular meshwork does not filter, while the posterior pigmented portion of the trabecular meshwork does. 


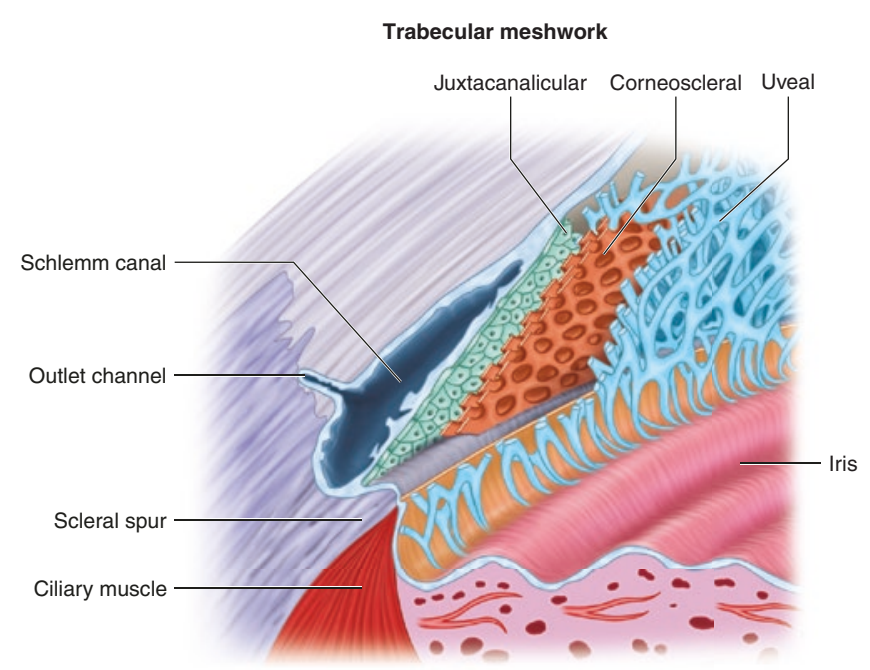

Fig. 2.1 Three layers of trabecular meshwork (shown in cutaway views): uveal, corneoscleral, and juxtacanalicular

This is clinically important as any trans-trabecular devices should target the posterior pigmented trabecular meshwork if the goal is the maximize flow into Schlemm's canal.

\subsection{Schlemm's Canal}

Schlemm's canal is an endothelial-lined circular tube with one of the highest hydraulic conductivities in the body [6]. Its pores, which range in size from 0.1 to 3 $\mu \mathrm{m}$ in diameter, allow passage not only of AH but also of particulate matter such as cells and ferritin. Additionally, the endothelial lining of Schlemm's canal changes in response to pressure gradient alterations. Elevated IOP leads to an increase in both the number and size of cellular out-pouchings or giant vacuoles while decreased IOP leads to a reduction [11]. AH is transmitted from the trabecular meshwork, through Schlemm's canal, to the distal venous collector system. AH exits Schlemm's canal through collector channels that are spaced at irregular intervals from the outer wall of the canal of Schlemm. They are approximately 25-30 in number and are predominately located in the nasal quadrants [12]. The collector channels ultimately lead to the episcleral venous system; there are two systems of intra-scleral channels: firstly, a direct system of four to six larger veins of Asher that drain directly into the episcleral venous system, and secondly, an indirect system of finer more numerous channels, which form an intrascleral plexus before ultimately draining into the veins of Asher. While the larger conjunctival veins of Asher are readily visible, the intrascleral plexus is difficult to examine.

Multiple studies suggest that dysfunction of the intrascleral outflow plexus is related to glaucoma; eyes with more advanced disease show downstream collector 
obstruction or atrophy [13] and functional outflow through human trabecular meshwork does not occur homogenously - there are regions of preferential flow adjacent to the location of collector channels. Corroborating this are studies showing that the total juxtacanalicular tissue adjacent to collector channels is expanded nearly twofold compared with the juxtacanalicular regions between collector channels [14]. As canal-based MIGS procedures aim to improve the flow of AH into the venous collector channels, estimating functionality preoperatively or intraoperatively would provide valuable information for both patient selection and prognostication. The finding of an "episcleral venous fluid wave", seen as downstream visible blanching of veins, may be a surrogate marker of anatomic patency of the conventional outflow system from the anterior chamber to the episcleral and conjunctival collectors [15].

\subsection{Uveoscleral Outflow}

The second route for AH outflow within the eye is through the unconventional outflow pathway (or uveoscleral pathway). The characterization of this pathway was first provided by Anders Bill in his pioneering work that estimated the outflow using tracer studies [16]. Unlike the trabecular outflow route, the uveoscleral outflow route is not a distinctive structural pathway with channels and tubes. Rather, $\mathrm{AH}$ passes through, around and between tissues of the ciliary muscle, supraciliary space and suprachoroidal space. Compared to the conventional pathway, the uveoscleral pathway is less well understood. Nonetheless, new devices that can provide surgical access to these spaces have led to a renewed interest in this anatomical region.

The anterior portion of the ciliary body extends into the chamber angle and there is no epithelial barrier between the anterior chamber and the ciliary muscle [17]. Similarly, there is no continuous cellular layer on the anterior iris face, so aqueous has direct access from the anterior chamber to the interstitial spaces of the ciliary muscle, and then through to the supraciliary and suprachoroidal spaces [16].

The supraciliary space is a narrow area between the outer surface of the ciliary body and the internal surface of the sclera anteriorly. Posteriorly, the suprachoroidal space is located between the choroid and the internal surface of the sclera. This subspace is approximately $30 \mathrm{~nm}$ thick and is composed of layers of pigmented collagenous processes derived from each tissue, forming a delicate collagen meshwork [18]. This space forms a transitional zone between the choroid and sclera and does not contain overt fluid under normal physiologic conditions.

The mechanism of how fluid from the supraciliary and suprachoroidal spaces exits the eye remains contested: Bill traced the route of radioactive-labelled proteins and other large molecules and proposed that the fluid seeps through sclera and episclera by diffusion into the orbit and then is absorbed by the orbital vasculature [16, $19,20]$. In contrast, Barany and others have suggested that the fluid is osmotically absorbed by the choroid and passes into the vortex veins [21-23].

Evidence of the potential IOP-lowering effect of the suprachoroidal space is derived from the clinical observation that a cyclodialysis cleft from trauma often 
leads to hypotony. However, harnessing a cyclodialysis cleft to control IOP has remained challenging due to uncontrolled low pressures and then conversely pressure spikes on closure of the cleft. A number of new MIGS devices target this space with the view to obtaining a controlled IOP with appropriate pressure reduction and minimal hypotony.

\subsection{Physiological Characteristics of Unconventional Outflow}

Aqueous entry into the uveoscleral pathway begins through the interstitial spaces of the ciliary muscle, and ciliary muscle tone has an important influence on outflow. Administration of pilocarpine, which causes contraction of the ciliary muscle fibres and compression of extracellular space, causes uveoscleral outflow to decrease by 90\% in cynomolgus monkeys [24]. In contrast, administration of atropine has the opposite effect: it causes relaxation of the muscle fibres, expansion of the extracellular space and thereby increases uveoscleral outflow [25]. Various prostaglandins also increase uveoscleral outflow by modifying the extracellular matrix between ciliary muscle bundles, thus reducing outflow resistance and allowing increased flow through these spaces [26].

Measuring outflow of the uveoscleral pathway is challenging because of intrinsic challenges in measuring the flow rate. Measurements can either be direct or indirect. Direct measurements involve injecting a tracer molecule into the anterior chamber and measuring its accumulation in ocular tissues and blood. While accurate, these tests are invasive and thus not generally suitable for human subjects. Only one study has reported direct measurements of uveoscleral outflow in the living human eye: Bill and Phillips [16] measured outflow in two normal eyes that were not receiving topical pilocarpine or atropine and found uveoscleral outflow accounted for 4-14\% of total outflow.

Indirect techniques calculate uveoscleral outflow using a modified Goldmann equation, which requires the measurement of four other parameters, each with inherent variability. This method tends to yield large standard deviations with considerable variability.

These limitations notwithstanding, the uveoscleral outflow pathway appears to be relatively insensitive to IOP differences, even over the range of 4 to $35 \mathrm{mmHg}$ [19]. This observation in part has meant that the majority of surgical targets to lower IOP have focused on the pressure-dependent trabecular outflow system. However, once the ciliary muscle is bypassed (through a shunt or a cyclodialysis cleft), most of the resistance it offers is lost [27] and the uveoscleral pathway becomes pressure dependent, with outflow increasing fourfold [28]. When the uveoscleral pathway is turned into a pressure-dependent pathway, as noted above, its capability of lowering IOP is so significant that the postoperative IOP can reach the low teens or single digits [29-31]. 


\subsection{Conjunctival Lymphatic System}

The human lymphatic system plays an important role in body fluid homeostasis, lipid absorption and immune function [31-33]. Fundamentally, the lymphatic system removes excess arterial fluid that is unable to be absorbed by the venous system from the interstitial space and acts to enhance immune surveillance. Traditionally seen as passive channels for fluid and immune cells, recent discoveries have drastically changed our view of lymphatic vasculature, which lags far behind our knowledge of the vascular system. Lymphatic vessels are now appearing to have diverse functions with remarkable specialization depending on tissue microenvironment [34].

Despite this limited knowledge, it appears conjunctival lymphatics are particularly important for the success of glaucoma surgical outcomes [35-37]. In the normal eye, conjunctival lymphatics are not involved in $\mathrm{AH}$ flow pathways, and lymphatics have no communication with conjunctival veins [38]. However, glaucoma filtering surgery alters the normal pathways. Aqueous humour is diverted into the subconjunctival space, which is equivalent to interstitial tissue fluid, where conjunctival lymphatic vessels exist. Animal studies confirm that the presence of lymphatic drainage pathways is associated with persistence of subconjunctival drainage pathways, which in turn play a key role in determining surgical outcomes of glaucoma filtration surgery [39]. Thus, understanding conjunctival lymphatic drainage is critical to optimize glaucoma therapeutic interventions.

Conjunctival lymphatics remain difficult to study because of their transparent, colourless nature and very thin vessel walls with absent basement membrane or pericytes. The lymphatic system is a series of unidirectional, thin-walled vessels that transport lymph to the lymphatic nodes, which eventually empty into the blood veins via the thoracic duct.

Conjunctival lymphatics in monkeys start with blind-ended terminals located in the superficial conjunctiva between the epithelium and Tenon's capsule [40]. These tubular vessels are of uneven calibre with numerous branch communications that are responsible for the initial drainage of interstitial fluid. The mechanism of fluid uptake appears to be transient fluid pressure gradients between the interstitial fluid and the initial lymphatic [41, 42]. The fluid then drains into valved precollectors, which are mostly located in the deep layer under Tenon's capsule. These connect to larger collectors and eventually empty into the preauricular and submaxillary lymph nodes $[43,44]$. The lymphatics appear to be relatively evenly distributed in the bulbar conjunctiva, with no difference between each quadrant or between the limbus or fornix regions.

Our knowledge of conjunctival lymphatics is still rudimentary, but an understanding of this system's role in interstitial fluid drainage is crucial to optimizing and targeting aqueous drainage in glaucoma therapy. Understanding the lymphatic vessels structure and function, distribution in the conjunctiva and eventually their functional assessment prior to filtration surgery will have significant implications for surgical glaucoma treatments that create a conjunctival bleb. 


\subsection{Conclusions}

Lowering IOP has been central to glaucoma care for over a century. New surgical devices are able to exploit different aspects of aqueous outflow to reduce IOP. A complete understanding of outflow pathways is important to develop new treatment strategies, improve current ones, and to better target the right operation for particular glaucoma subtypes.

\section{References}

1. Alm A, Nilsson SF. Uveoscleral outflow—a review. Exp Eye Res. 2009;88(4):760-8.

2. Toris CB, Koepsell SA, Yablonski ME, et al. Aqueous humor dynamics in ocular hyptertensive patients. J Glaucoma. 2002;11(3):253.

3. Toris $\mathrm{CB}$, Yablonski ME, Wang YL, et al. Aqueous humor dynamics in the aging human eye. Am J Ophthalmol. 1999;127(4):407.

4. Townsend DJ, Brubaker RF. Immediate effect of epinephrine on aqueous formation in the normal human eye as measured by fluorophotometry. Invest Ophthalmol Vis Sci. 1980;19(3):256.

5. Brubaker RF. Measurement of uveoscleral outflow in humans. J Glaucoma. 2001;10(5 Suppl 1):S45.

6. Johnson M. What controls aqueous humour outflow resistance? Exp Eye Res. 2006;82:545.

7. Brubaker RF. Flow of aqueous humor in humans. Invest Ophthalmol Vis Sci. 1991;32:3145.

8. Larsson LI, Rettig ES, Sheridan PT, et al. Aqueous humor dynamics in low-tension glaucoma. Am J Ophthalmol. 1993;116:590.

9. Tamm ER. The trabecular meshwork outflow pathways: structural and functional aspects. Exp Eye Res. 2009;88:648.

10. Moses RA, Grodski WJ Jr. The scleral spur and scleral roll. Invest Ophthalmol Vis Sci. 1977;16(10):925.

11. Johnstone MA, Grant WG. Pressure-dependent changes in structures of the aqueous outflow system of human and monkey eyes. Am J Ophthalmol. 1973;75(3):365-83.

12. Kagemann L, Wollstein G, Ishikawa H, et al. Identification and assessment of Schlemm's canal by spectral-domain optical coherence tomography. Invest Ophthalmol Vis Sci. 2010;51:4054-9.

13. Nesterov AP. Pathological physiology of primary open angle glaucoma: the aqueous circulation. In: Cairns JE, editor. Glaucoma, vol. I. New York: Grune and Stratton; 1986. p. $335-6$.

14. Hann CR, Fautsch MP. Preferential fluid flow in the human trabecular meshwork near collector channels. Invest Ophthalmol Vis Sci. 2009;50(4):1692-7.

15. Fellman RL, Feuer WJ, Grover DS. Episcleral venous fluid wave correlates with trabectome outcomes: intraoperative evaluation of the trabecular outflow pathway. Ophthalmology. 2015;122:2385-91.e1.

16. Bill A, Phillips CI. Uveoscleral drainage of aqueous humour in human eyes. Exp Eye Res. 1971;12:275-81.

17. Nilsson SFE. The uveoscleral outflow routes. Eye. 1997;11:149-54.

18. Hogan MH, Alvarado JA, Weddell JE. Histology of the human eye-an atlas and textbook. Philadelphia: Saunders; 1971. p. 320.

19. Bill A. Conventional and uveo-scleral drainage of aqueous humour in the cynomolgus monkey (Macaca irus) at normal and high intraocular pressures. Exp Eye Res. 1966;5:45-54.

20. Bill A. Blood circulation and fluid dynamics in the eye. Physiol Rev. 1975;55:383-416.

21. Barany EH. Pseudofacility and uveoscleral outflow routes. Munich: Basel, Karger; 1967. 
22. Pederson JE, Gassterland DE, MacLellan HM. Uveoscleral aqueous outflow in the rhesus monkey: importance of uveal reabsorption. Invest Ophthalmol Vis Sci. 1977;16:1008-17.

23. Sherman SH, Green K, Laties AM. The fate of anterior chamber fluorescein in the monkey eye. 1. The anterior chamber outflow pathways. Exp Eye Res. 1978;27:159-73.

24. Crawford K, Kaufman PL. Pilocarpine antagonizes prostaglandin F2 alpha-induced ocular hypotension in monkeys. Evidence for enhancement of uveoscleral outflow by prostaglandin F2 alpha. Arch Ophthalmol. 1987;105(8):1112-6.

25. Bill A, Walinder P. The effects of pilocarpine on the dynamics of aqueous humor in a primate (Macaca irus). Investig Ophthalmol. 1966;5(2):170-5.

26. Lutgen-Drecoll E, Tamm E. Morphological study of the anterior segment of cynomolgus monkey eyes following treatment with prostaglandin F2a. Exp Eye Res. 1988;47(5):761-9.

27. Bill A. The routes for bulk drainage of aqueous humor in rabbits with and without cyclodialysis. Doc Ophthalmol. 1966;20:157-69.

28. Suguro K, Toris CB, Pederson JE. Uveoscleral outflow following cyclodialysis cleft in the monkey eye using a fluorescent tracer. Invest Ophthalmol Vis Sci. 1985;26:810-3.

29. Emi K, Pederson JE, Toris CB. Hydrostatic pressure of the suprachoroidal space. Invest Ophthalmol Vis Sci. 1989;30:233-8.

30. Skaat A, Sagiv O, Kinori M, Simon GJ, Goldenfeld M, Melamed S. Gold Micro-Shunt implants versus Ahmed Glaucoma Valve: long-term outcomes of a prospective randomized clinical trial. J Glaucoma. 2016;2:155-61.

31. Gausas RE, Gonnering RS, Lemke BN, et al. Identification of human orbital lymphatics. Ophthal Plast Reconstr Surg. 1999;15:252-9.

32. Schmid-Schonbein GW. Microlymphatics and lymph flow. Physiol Rev. 1990;70(4): 987-1028.

33. Steenbergen JM, Lash JM, Bohlen HG. Role of a lymphatic system in glucose absorption and the accompanying microvascular hyperemia. Am J Phys. 1994;267(4 Pt 1):G529-35.

34. Petrova TV, Koh GY. Organ-specific lymphatic vasculature: from development to pathophysiology. J Exp Med. 2018;215(1):35-49.

35. Ritch R, Shields MB, Krupin T. The glaucomas. St Louis: The C.V. Mosby Company; 1989. p. $1-748$.

36. Teng CC, Chi HH, Katzin HM. Histology and mechanism of filtering operations. Am J Ophthalmol. 1959;47:16-34.

37. Singh D. A new clue to lymphatic drainage. Rev Ophthalmol. 2002;9:12.

38. Yu D-Y, Morgan WH, Sun X, et al. The critical role of the conjunctiva in glaucoma filtration surgery. Prog Retin Eye Res. 2009;28:303-28.

39. Morgan WH, Balaratnasingam C, Guibilato A, et al. The use of trypan blue as a tracer to outline aqueous flow. J Ophthalmol Photogr. 2005;27:79-81.

40. Guo W, Zhu Y, Yu PK, et al. Quantitative study of the topographic distribution of conjunctival lymphatic vessels in the monkey. Exp Eye Res. 2012;94:90-7.

41. Moriondo A, Mukenge AS, Negrini D. Transmural pressure in rate initial subpleural lymphatics during spontaneous or mechanical ventilation. Am J Physiol Heart Circ Physiol. 2005;289:H269.

42. Negrin D, Moriondo A, Mukenge S. Transmural pressure during cardiogenic oscillations in rodent diaphragmatic lymphatic vessels. Lymph Res Biol. 2004;2:69-81.

43. Singh D, Singh RSJ, Singh K, et al. The conjunctival lymphatics system. Ann Ophthalmol. 2003;35:99-104.

44. Sugar HS, Riazi A, Schaffner R. The bulbar conjunctival lymphatics and their clinical significance. Trans Am Acad Ophthalmol Otolaryngol. 1957;61:212-23. 
Open Access This chapter is licensed under the terms of the Creative Commons Attribution 4.0 International License (http://creativecommons.org/licenses/by/4.0/), which permits use, sharing, adaptation, distribution and reproduction in any medium or format, as long as you give appropriate credit to the original author(s) and the source, provide a link to the Creative Commons license and indicate if changes were made.

The images or other third party material in this chapter are included in the chapter's Creative Commons license, unless indicated otherwise in a credit line to the material. If material is not included in the chapter's Creative Commons license and your intended use is not permitted by statutory regulation or exceeds the permitted use, you will need to obtain permission directly from the copyright holder. 